\title{
Advance Statements About Medical Treatment
}

In April 1995 the British Medical Association (BMA) published a Code of Practice, Advance Statements About Medical Treatment. This was in response to requests for advice from health professionals consulted by patients with, or wishing to make, advance statements about their future medical care. This Code of Practice has subsequently been endorsed by the Conference of Royal Colleges and the Royal College of Nursing.

The Code provides advice to health professionals on a range of advance statements. It is concerned not only with clear instructions refusing some or all medical procedures (advance directives), but also with statements which reflect an individual's aspirations and preferences, statements of general belief and aspects of life which an individual values, and with statements which name another person who should be consulted, on the individual's behalf, about medical decisions.

The BMA is not in the position of encouraging people to make advance statements but believes that people should have the opportunity to plan for their future care if they so wish. While making decisions in advance may help to ensure that the care they receive is what they would want in the circumstances, there are disadvantages. The way healthy people feel about illness before they have experienced it may be quite different to how they feel when it happens. It is also possible that a badly worded statement may be implemented in circumstances the patient had not foreseen. Health professionals should ensure that patients are aware of the advantages and disadvantages before deciding to make an advance statement.

\section{The legal position}

There is currently no legislation covering advance statements but it is now clear, in common law, that competent, informed adults have a legal right to refuse medical procedures in advance and that an unambiguous and informed advance directive (refusal) can be as valid as a contemporaneous decision. Thus, where the refusal addresses the situation which has actually occurred, health professionals may be legally bound to comply with the terms of the advance directive. If doubt exists about what the individual intends, the law supports a presumption in favour of providing clinically appropriate treatment. However, health professionals may be legally liable if they disregard the terms of an advance directive, if the directive is known to them, is clear and unambiguous and is applicable to the circumstances.
Health professionals who follow the terms of a clear advance directive and exercise due care and attention would be most unlikely to face prosecution.

Advance statements expressing preferences about treatment decisions or requesting certain treatments are not legally binding. In England and Wales, views expressed by a third party about medical care are also not binding on health professionals. The BMA believes, however, that wherever possible, such statements should be taken into account in deciding on the patient's best interests. In all circumstances, a contemporaneous decision by a competent individual overrides previously expressed statements by that person.

\section{Scope of advance statements}

People cannot authorise or refuse in advance procedures which they could not authorise or refuse contemporaneously. They cannot authorise unlawful procedures, such as euthanasia, nor can they insist upon futlle or inappropriate treatment. Although not stated in the law, the BMA believes that people should not be able to refuse, in advance, the provision of 'basic care'. This includes the administration of medication or the performance of any procedure which is solely or primarily designed to provide comfort to the patient or alleviate that person's pain, symptoms or distress. Women of childbearing age should consider the fact that an advance statement might be implemented at a time when they are pregnant and should be advised to consider inserting a waiver to cover pregnancy. In the case of young people under the age of majority, advance statements should be taken into account and accommodated if possible but can be overruled by a court or person with parental responsibility.

\section{Provision of information}

In order to make informed choices about advance statements patients have a legitimate expectation of being provided with information in an accessible form. Thus, health professionals should ensure that the foreseeable options and implications are adequately explained, admit to uncertainty when this is the case, and make reasonable efforts to discover if there is more specialised information available to pass on to the patient. In response to a request for assistance with advance statements, health professionals should ask 
whether the patient is mentally competent, whether the patient has sufficient knowledge of the medical condition and possible treatment options if there is a known illness, and whether the patient is being coerced into making decisions by other people.

\section{Format of statements}

Oral statements are likely to be legally valid if supported by appropriate evidence but there are clear advantages to recording general views and specific refusals in writing. Advance statements are an aid to, rather than a substitute for, open dialogue between patients and health professionals. There are no specific legal requirements concerning the format of advance statements but it is recommended as a minimum, that the following information is included: full name, address, name and address of general practitioner, whether advice was sought from health professionals, a clear statement of wishes or the name, address and telephone number of a person to be consulted, signature and the date the document was written and reviewed. It is recommended that the statement is reviewed on a regular basis and at least every five years. The only minimum requirements for legal validity are that the patient is competent at the time of making the statement, is aware of the implications of the decision and that the circumstances match those in the statement.

Advance Statements About Medical Treatment is avallable from BMJ Publishing Group, PO Box 295, London WC1H 9TE (tel: 01713836185 ) and costs $\$ 4.95$ for BMA members and $\$ 5.95$ for non-members.

Advance Statements About Future Medical Treatment. A

Guide for Patients can be purchased from the Patient's Assoctation, 8 Guilford Street, London WCIN IDT (tel: 0171 242 346).

\section{Continuing Professional Development Validation}

From the 1 January 1996, the application form for the validation of all CPD events will be available on request from the College. Completed forms relating to national or international CPD events should be returned to the College to be processed. Completed forms relating to regional or local events should be returned to the CPD Deputy Regional Adviser (details available on the application form).
For more information please contact Mrs Jean Wales, CPD Officer or Ms Pauline Taggart, CPD Administrator at the following address: The Royal College of Psychiatrists, 17 Belgrave Square, London SW1X 8PG (Tel: 0171-235 2351 extension 270 or 112).

\section{Log Books or Personal Training Files - A College Working Party}

A working party has been established at the request of the Education Committee and the Tutor's Sub-Committee, with the support of the Dean. Its remit is to supervise an 18-month evaluation of a pilot document (the Log Book or Personal Training Fule) which can be used by trainees at the current senior house officer (SHO) and registrar grades as a means of facilitating the recording and planning of their training in psychiatry.

The pilot document, available in the form of a slim, loose-leaf A4 folder, represents a compromise between portability and ease of use. It is intended to be held by the trainee, and to remain their personal property. Space is allowed to record experience in individual posts, to set educational 